\title{
PENGARUH MODEL PEMBELAJARAN PBL (PROBLEM BASED LEARNING) TERHADAP KETERAMPILAN PROSES DAN HASIL BELAJAR SISWA DALAM PEMBELAJARAN FISIKA DI SMA
}

\author{
Syarifah Rita Zahara \\ Pendidikan Fisika FKIP Universitas Malikussaleh \\ E-mail: syarifah_ritaz@yahoo.com
}

\begin{abstract}
Abstrak: Penelitian difokuskan pada pengaruh PBL terhadap keterampilan proses sains siswa dan prestasi belajar fisika siswa. Tujuan dari penelitian ini adalah (1) untuk mendeskripsikan ketrampilan proses sains siswa dengan menggunakan model Problem Based Learning dalam pembelajaran fisika, (2) menguji pengaruh model Pembelajaran Berbasis Masalah terhadap prestasi belajar fisika siswa dalam pembelajaran fisika. Jenis penelitian ini adalah percobaan dengan menggunakan post-test only control design. Sampel penelitiannya adalah X1A sebagai kelas eksperimen dan X12B sebagai kelas kontrol. Teknik pengumpulan data adalah observasi, uji, dokumentasi, wawancara dan portofolio. Teknik analisis data menggunakan analisis deskriptif dan Independent Sample T-Test oleh SPSS versi 16. Hasil penelitian ini adalah (1) rata-rata nilai keterampilan proses sains siswa adalah 78, (2) prestasi fisika siswa diperoleh hasil analisis Independen. -Sample T-test Sig. (1-tailed) sebesar 0,002. Penelitian dapat disimpulkan bahwa (1) keterampilan proses sains siswa rata-rata dalam kriteria yang baik, (2) ada pengaruh model pembelajaran berbasis masalah terhadap prestasi belajar fisika
\end{abstract}

Kata kunci : model pembelajaran berbasis masalah, keterampilan proses sains, prestasi fisika.

\section{THE EFFECT OF LEARNING MODELS PBL (PROBLEM BASED LEARNING) ON PROCESS SKILLS AND STUDENT LEARNING RESULTS IN LEARNING PHYSICS IN HIGH SCHOOL}

\begin{abstract}
The study focused on the effect of PBL on student science process skills and student physics learning achievement. The purpose of this study are (1) to describe students 'science process skills using the Problem Based Learning model in physics learning, (2) to examine the effect of Problem Based Learning models on students' physics learning achievement in physics learning. This type of research is an experiment using post-test only control design. The research sample is $\mathrm{X} 1 \mathrm{~A}$ as the experimental class and $\mathrm{X} 12 \mathrm{~B}$ as the control class. Data collection techniques are observation, testing, documentation, interviews and portfolios. Data analysis techniques used descriptive analysis and Independent Sample TTest by SPSS version 16. The results of this study were (1) the average value of students 'science process skills was 78, (2) students' physics achievements obtained the results of independent analysis. -Sample T-test Sig. (1-tailed) of 0.002. The research can be concluded that (1) students' science process skills are on average in good criteria, (2) there is an influence of problem-based learning models on physics learning achievement
\end{abstract}

Keywords: problem based learning model, science process skills, physics achievement.

\section{PENDAHULUAN}

Fisika merupakan bagian dari Ilmu Pengetahuan Alam (IPA) mempelajari tentang kejadian ilmiah. Fisika mempelajari gejala-gejala dan kejadian alam melalui serangkaian proses yang dikenal dengan proses ilmiah yang dibangun atas dasar sikap ilmiah dan hasilnya berwujud produk ilmiah berupa konsep, hukum, teori yang berlaku secara universal (Trianto, 2011:137). 
Dapat dikatakan bahwa hakikat fisika adalah ilmu pengetahuan yang mempelajari gejala-gejala melalui serangkaian proses yang dikenal dengan proses ilmiah yang dibangun atas dasar sikap ilmiah dan hasilnya terwujud sebagai produk ilmiah yang tersusun atas tiga komponen terpenting berupa konsep, prinsip dan teori yang berlaku secara universal. Tujuan pembelajaran fisika secara umum adalah menguasai pengetahuan, konsep dan prinsip fisika, serta mempunyai keterampilan mengembangkan pengetahuan, keterampilan dan sikap percaya diri sehingga dapat diterapkan dalam kehidupan sehari-hari dan sebagai bekal untuk melanjutkan pendidikan pada jenjang yang lebih tinggi (Depdiknas 2003:7). Menurut Bektiarso (2000:11), hakikat mempelajari fisika adalah membahas, mengkaji dan membuktikan adanya fakta dan asumsi tentang gejala-gejala fisika. Sehingga dalam pembelajaran fisika siswa dituntut untuk memahami dan mampu mengaplikasikan materi fisika dalam kehidupan sehari-hari.

Masalah utama pembelajaran yang masih banyak ditemui adalah tentang rendahnya hasil belajar peserta didik. Berdasarkan kajian data, diketahui bahwa hasil belajar siswa SMA masih rendah dalam hal pencapaian nilai kriteria ketuntasan minimal (KKM 75), terutama untuk mata pelajaran IPA (Rosidah 2014:66). Davis (dalam Rusman, 2013:229) mengemukakan, salah satu kecenderungan yang sering dilakukan adalah melupakan hakikat pembelajaran yang sesungguhnya di mana seharusnya menekankan pada belajarnya siswa, dan bukan pada mengajarnya guru. Oleh karena itu, pemilihan model pembelajaran dalam pembelajaran IPA khusunya bidang fisika haruslah dilatarbelakangi oleh suatu faktor yang kontekstual dan dilandaskan pada pertimbangan untuk menempatkan siswa sebagai subjek belajar yang tidak hanya menerima (pasif) ketika belajar di dalam kelas, namun juga harus dapat menempatkan siswa sebagai insan yang alami, memiliki pengalaman, keinginan, dan pikiran yang dapat dimanfaatkan untuk belajar, baik secara individu maupun kelompok sehingga keterampilan-keterampilan belajar siswa diharapkan akan meningkat. Peningkatan keterampilan terutama keterampilan proses akan diikuti pula oleh peningkatan hasil belajar, sehingga kualitas pendidikan dapat menjadi lebih baik. Menurut Wahyudi (2015:6) Keterampilan proses sains merupakan keterampilan yang melibatkan segenap kemampuan siswa dalam memperoleh pengetahuan berdasarkan fenomena.

Menurut Arends (dalam Trianto, 2011:51), model pembelajaran mengacu pada pendekatan pembelajaran yang akan digunakan, termasuk didalamnya tujuan-tujuan pengarahan, tahap-tahap dalam kegiatan pembelajaran, lingkungan pembelajaran, dan pengelolaan kelas.Salah satu model pembelajaran yang memiliki kriteria di atas adalah model problem based learning (PBL).

Model Problem Based Learning (PBL) merupakan salah satu bentuk perubahan polapikir dari teacher centered menuju students centered. Menurut KuoShu Huang ( dalamBungel, 2014:47) PBL adalah desain kurikulum yang diidentifikasi siswa tidak sebagai penerima pasif pengetahuan tetapi sebagai pemecah masalah yang bisa mengembangkan pengetahuan. Dalam model PBL, siswa tidak hanya harus memahami konsep yang relevan dengan masalah yang menjadi pusat perhatian tetapi juga memperoleh pengalaman belajar yang berhubungan dengan keterampilan menerapkan metode ilmiah dalam memecahkan masalah dan menumbuhkan pola berpikir kritis. Model ini merupakan inovasi pembelajaran yang dirancang untuk membantu peserta didik memahami teori secara mendalam melalui pengalaman belajar praktik-empirik.

Pada penelitian sebelumnya yang dilakukan oleh: Sumarji (2009) dengan judul " Penerapan Model Pembelajaran Problem Based Learning untuk Meningkatkan Motivasi dan Kemampuan Pemecahan Masalah Ilmu Statika dan Tegangan di SMK" telah mencapai keberhasilan dalam tujuan penelitiannya, dan Sumaji menyimpulkan bahwa : 1) penerapan model PBL dapat meningkatkan motivasi siswa dalam pemecahan masalah Mata Pelajaran Ilmu Statika dan Tegangan di kelas X TKB 1 ; 2) Penerapan pembelajaran model PBL dapat meningkatkan kemampuan siswa dalam memecahkan masalah Mata Pelajaran Ilmu Statika 
dan Tegangan di kelas X TKB1 SMK Negeri 1 Singosari.

Berdasarkan uraian di atas, maka peneliti mengambil judul "Pengaruh Model Pembelajaran PBL (Problem Based Learning) Terhadap Keterampilan Proses dan Hasil Belajar Siswa dalam Pembelajaran Fisika di SMA".

Tujuan penelitian ini adalah (1) Mendiskripsikan keterampilan proses siswa menggunakan model pembelajaran PBL (Problem Based Learning) dalam pembelajaran fisika di SMA, (2) Mengkaji pengaruh model pembelajaran PBL (Problem Based Learning) terhadap hasil belajar siswa dalam pembelajaran fisika di SMA.

\section{METODE}

Langkah-langkah pembelajaran menggunakan model $P B L$ adalah sebagai berikut: (1) Pendahuluan merupakan upaya guru untuk menyampaikan tujuan pembelajaran. (2) Orientasi masalah merupakan upaya guru untuk menyajikan permasalahan yang sesuai dengan kehidupan nyata melalui LKS. (3) Mengorganisasikan siswa untuk belajar merupakan upaya guru untuk membantu siswa memahami dan mendefinisikan permasalahan pada LKS serta menyiapkan langkah-langkah penyelidikan. (4) Membantu menyelidiki secara mandiri atau kelompok merupakan upaya guru untuk membimbing siswa melalukan percobaan untuk memperoleh informasi. (5) Mengembangkan dan menyajikan hasil kerja merupakan upaya guru untuk membantu siswa menyiapkan hasil percobaan serta menjawab analisa data sebagai sebuah laporan. (6) Menganalisis dan mengevaluasi hasil pemecahan masalah merupakan upaya guru untuk mengevaluasi proses pemecahan masalah.

Jenis penelitian adalah true experimental. Penelitian ini dilaksanakan di SMA Negeri 4 Bireuen pada semester genap tahun ajaran 2017/2018. Responden penelitian ditentukan setelah uji homogenitas. Penentuan sampel dengan metode cluster random sampling. Desain penelitian menggunakan post-test only control design.

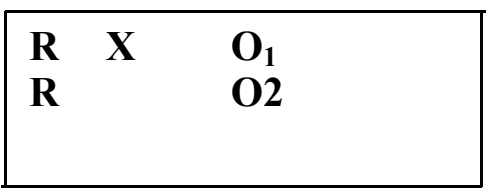

Gambar 1. Post-test only control design

Keterangan:

$\mathrm{R}=$ Random

$\mathrm{X}=$ Perlakuan proses belajar mengajar menggunakan model PBL

$\mathrm{O}_{1} \quad=$ nilai hasil belajar

$\mathrm{O}_{2} \quad=$ nilai hasil belajar

Teknik dan instrument pengumpulan data yang digunakan dalam penelitian ini adalah lembar observasi keterampilan proses sains menggunakan perangkat tes hasil belajar, portofolio menggunakan lembar portofolio keterampilan proses sains, dokumentasi berupa daftar nama, nilai ulangan fisika sebelum penelitian, dan foto kegiatan pembelajaran saat penelitian, wawancara menggunakan pedoman wawancara. Teknik analisis data menggunakan criteria keterampilan proses sains siswa yang terdapat pada Tabel 1 dan uji Independent Samples T-Test dengan program SPSS versi 16. 
Tabel 1.Kriteriaketerampilan proses siswa

\begin{tabular}{ll}
\hline Interval & Kriteria \\
\hline $75 \% \leq$ Skor $\leq$ & Baik \\
$100 \%$ & \\
$55 \% \leq$ Skor $\leq$ & CukupBaik \\
$100 \%$ & KurangBaik \\
$40 \% \leq$ Skor $\leq$ & TidakBaik \\
Skor $<40 \%$ &
\end{tabular}

(Widayanto, 2009

\section{HASIL DAN PEMBAHASAN}

Keterampilan proses sains siswa

Penelitian keterampilan proses sains siswa diperoleh dari dua metode pengambilan data, yaitu melalui metode observasi yang dilakukanoleh observer serta metode portofolio yang diperoleh dari hasil pekerjaan siswa pada lembar kerja siswa yang dinilai oleh peneliti. Adapun rekapitulasi keterampilan proses sains dapat dilihat pada Tabel 2.

Tabel 2. Hasil rekapitulasi keterampilan proses sains

\begin{tabular}{|c|c|c|c|c|}
\hline \multirow[b]{2}{*}{ Indikator KPS } & \multicolumn{3}{|c|}{ Nilai } & \multirow[b]{2}{*}{ Kriteria } \\
\hline & Pertemuan 1 & Pertemuan 2 & Rata-rata & \\
\hline Melakukaneksperimen & 73 & 78 & 76 & Baik \\
\hline Melakukan observasi & 81 & 92 & 87 & Baik \\
\hline Memproses data & 76 & 83 & 80 & Baik \\
\hline Mengkomunikasikan & 79 & 74 & 77 & Baik \\
\hline Menyusun hipotesis & 74 & 90 & 82 & Baik \\
\hline Mengklasifikasikan & 72 & 82 & 77 & Baik \\
\hline \multirow[t]{2}{*}{ Menyimpulkan } & 67 & 77 & 73 & Cukup Baik \\
\hline & Rata-rata & & 78 & Baik \\
\hline
\end{tabular}

Tabel 2 menyatakan bahwa aspek keterampilan proses sains siswa yang paling rendah adalah menyimpulkan hasil penelitian yaitu 72 . Pada saat proses pembelajaran berlangsung terlihat bahwa siswa lebih aktif terutama saat melakukan eksperimen dan melakukan pengamatan. Namun, pada aspek menyimpulkan hasil eksperimen, siswa masih belum terbiasa untuk mengungkapkan pendapatnya. Serta masih adanya rasa takut dan kurang rasa percaya diri ketika pendapatnya berbeda dengan kelompok lain. Hal ini yang menyebabkan aspek menyimpulkan memiliki nilai yang paling rendah daripada aspek lainnya.

Aspek keterampilan proses sains siswa yang paling tinggi adalah keterampilan melakukan observasi dengan perolehan nilai 87. Hal ini dikarenakan pengamatan berorientasi pada penyajian masalah nyata yang sering mereka temui dalam kehidupan sehari - hari sebagai topik pembelajaran, sehingga siswa akan lebih tertarik untuk memperhatikan.

Berdasarkan uraian di atas dapat disimpulkan bahwa penerapan model problem based learning dapat merangsang peran aktif siswa dalam mengikuti pembelajaran. Hal ini dibuktikan dengan nilai nilai rata-rata keterampilan proses sain siswa diperoleh nilai 78 maka keterampilan proses sains siswa tersebut dapat dikategorikan "baik". Hal ini sesuai dengan penelitian Prima dan Kaniawati (2011) dengan hasil penelitian "adanya peningkatan 
keterampilan proses sains yang lebih tinggi pada kelas eksperimen dengan perbedaan sangat signifikan dibandingkan dengan peningkatan keterampilan proses sains pada kelas kontrol".Sama halnya dengan penelitian Purba (2015) dengan hasil penelitian "Keterampilan proses sains siswa yang diajarkan dengan model pembelajaran problem bassed learning lebih baik dari keterampilan proses sains siswa yang diajarkan dengan model pembelajaran konvensional".

HasilBelajar

Hasil belajar yang diukur dalam penelitian ini adalah ranah kognitif. Nilai ranah kognitif diperoleh berdasarkan hasil tes (post-test). Adapun hasil belajar siswa pada kelas eksperimen dan kelas kontrol seperti pada Tabel 3

$\frac{\text { Tabel 3. Hasil belajar siswa kelas eksperimen dan kelas kontrol }}{\text { Kelas }}$

\begin{tabular}{cc}
\hline Eksperimen & 72 \\
\hline Kontrol & 63 \\
\hline
\end{tabular}

Tabel 3 menunjukkan bahwa nilai hasil belajar pada kelas eksperimen lebih baik dari pada kelas control. Berdasarkan analisis Independent sample t-test hasil belajar kompetensi pengetahuan $\operatorname{sig}(1$-tailed) sebesar 0,002 atau $0,002<0,05$. Jika dikonsultasikan dengan pedoman pengambilan keputusan maka hasil belajar siswa kelas eksperimen lebih baik dari pada kelas kontrol (Ha diterima, Ho ditolak), artinya model problem based learning berpengaruh signifikan terhadap hasil belajar fisika siswa. Dengan demikian dapat disimpulkan bahwa hasil belajar fisika yang diajarkan dengan menggunakan problem based learning lebih baik dari pada yang menggunakan model yang biasa digunakan di sekolah. Hal ini sesuai dengan penelitian Widodo (2013) dengan hasil penelitian "Metode problem based learning dapat meningkatkan hasil belajar siswa kelas VIIA di MTs Donomulyo, Nanggulan, Kulon Progo pada pokok bahasan wujud zat dan perubahannya". Samahalnya dengan penelitian Wulandari (2013) dengan hasil penelitian "Terdapat perbedaan hasil belajar yang signifikan antara siswa yang diajar dengan metode PBL dengan siswa yang diajar dengan metode pembelajaran demonstrasi. Hasil belajar siswa yang diajar dengan metode PBL lebih tinggi dibandingkan dengan siswa yang diajar dengan metode pembelajaran demonstrasi".

\section{KESIMPULAN DAN SARAN}

Berdasarkan pembahasan dan hasil analisis data penelitian yang telah diuraikan, maka dapat diambil kesimpulan sebagai berikut: (1) Keterampilan proses sains siswa dengan pembelajaran menggunakan model problem based learning diperoleh nilai rata-rata yang signifikan dan termasuk pada kategori baik, (2) Ada pengaruh model problem based learning terhadaphasil belajar siswa dalam pembelajaran sains di SMA.

Berdasarkan hasil penelitian dan pembahasan, maka saran yang diberikan sebagai berikut: (1) Bagi guru, dalam menggunakan model problem based learning perlu pengaturan waktu yang tepat agar proses KBM berjalan maksimal. Selain itu hendaknya jumlah kelompok tidak terlalu banyak agar setiap siswa mendapat tugas dalam setiap kelompoknya, (2) Bagi penelitilain, hasil penelitian ini diharapkan dapat dijadikan landasan untuk penelitian selanjutnya pada topik pembelajaran yang berbeda atau bahkan pada mata pelajaran yang berbeda, tentunya dengan memperhatikan kendala-kendala yang dialami. 


\section{DAFTAR PUSTAKA}

Bektiarso. 2000. Pentingnya Konsepsi Awal dalam Pembelajaran Fisika. Jurnal Saintifika Vol. 1 (1), hal 11-20.

Bungel. 2014. Penerapan Model Pembelajaran Problem Based Learning Untuk Meningkatkan Hasil Belajar Siswa Kelas Viii Smp Negeri 4 Palu Pada Materi Prisma.JurnalElektronikPendidik anMatematikaTadulako, Vol. 2 (5), hal45-53

Depdiknas. 2003. Standart Kompetensi mata pelajaran fisika SMA \& MA. Jakarta: Balitbang Depdiknas

Prima dan Kaniawati. 2011. Penerapan Model Pembelajaran Problem Based Learning Dengan Pendekatan Inkuiri Untuk Meningkatkan Keterampilan Proses Sains dan Penguasaan Konsep Elastisitas pada Siswa SMA. Jurnal pengajaran MIPA, Vol. 16(1), hal 179-184

Purba. 2015. Pengaruh Model Problem Based Learning (PBL) dengan Pemahaman Konsep Awal Terhadap Keterampilan Proses Sains (KPS) Siswa SMA. Jurnal pendidikan fisika indonesia, Vol 4 (2), hal 8-13

Rosidah. 2014.Penerapan Model Problem Based Learning (PBL) PadaPembelajaranHukum-HukumDasar Kimia DitinjauDariAktivitas Dan HasilBelajarSiswaKelas X IPA SMA Negeri 2 Surakarta Tahun Pelajaran 2013/2014. Jurnal Pendidikan Kimia, Vol. 3 (3), hal 66-75

Rusman. 2013. Model-model Pembelajaran: Mengembangkan Profesionalisme Guru. Jakarta: Rajagrafindo Persada.

Sumarji. 2009. Penerapan Model Pembelajaran Problem Based Learning untuk Meningkatkan Motivasi dan Kemampuan Pemecahan Masalah Ilmu Statika dan Tegangan di SMK. Jurnal Teknologi dan Kejuruan, Vol. 32(2), hal 129-140

Wahyudi. 2015. Pengaruh Problem Based Learning Terhadap Keterampilan Proses Sains Dan Hasil Belajar BiologiSiswaKelas X SMA Negeri Jumapolo Tahun Pelajaran 2013/2014. Jurnal Bio-Pedagogi, Vol. 4 (1), hal 5-11

Widayanto. 2009. Pengembangan Keterampilan Proses dan Pemahaman Siswa Kelas X Melalui Kit Optik. Jurna lpendidikan fisika indonesia, Vol. 5 (1), hal 1-7

Widodo.2013. Peningkatan Aktivitas Belajar dan Hasil Belajar Siswa dengan Metode Problem Based Learning pada Siswa Kelas VIIA MTs Negeri Donomulyo Kulon Progo Tahun Pelajaran 2012/2013. Jurnal fisika indonesia, Vol. XVII (49), hal32-35

Wulandari, Bekti. 2013. Pengaruh Problem Based Learning Terhadap Hasil Belajar Ditinjau Dari Motivasi Belajar PLC Di SMK. Jurnal Pendidikan Vokasi, Vol 3(2), hal 178-19 